\title{
Surgical wound irrigation: strategy for prevention of surgical site infection
}

\begin{abstract}
The surgical site infection (SSI) represents a serious public health problem due to its high rates of morbidity and mortality. Besides, it produces direct and indirect costs and prolonged hospital stay. Recently, the World Health Organization published the global guide for the prevention of surgical site infections with several strategies recommended. However, it is the first time the surgical wound irrigation has been placed in an important role in SSI prevention.

Currently, several studies refer to the use of antiseptics such as chlorhexidine gluconate $(\mathrm{CHG})$ in irrigation, creating a multimodal strategy for the use of CHG in FDA-approved pre, trans and postoperative activities. Indiscriminate application of substances, such as antibiotics, has become a challenge as it, at the end of the day, causes increases in antimicrobial resistance and failures in hospital treatment worldwide. This article serves to urge the comprehensive analysis of the published literature regarding surgical wound irrigation so as to create better documentation and research evidence that help the formation of a criterion for health personnel to prevent of infections associated with health care, particularly SSI.
\end{abstract}

Keywords: surgical wound irrigation, infection control, surgical site infection, perioperative nursing
Volume 3 Issue | - 2017

\author{
José J Escamilla Zamudio,' Gretta I Ramirez \\ 'Chávez,' María E Garduño Hernández² \\ 'Department of Nursing and Obstetrics, National Autonomous \\ University of México, México \\ ${ }^{2}$ Department of Education and Research, Biossmann, México
}

Correspondence: José J Escamilla Zamudio, Department of Nursing and Obstetrics, National Autonomous University of México, México, Tel 554940 7119,

Email jiescamillaz@unal.edu.co

Received: May 12, 2017 | Published: June 08, 2017

\section{Surgical would irrigation}

A recent prevalence study found that surgical site infections (SSI) were the most common healthcare-associated infection (HAI), accounting for $31 \%$ of all HAIs among hospitalized patients. ${ }^{1}$ The World Health Organization (WHO) report on the global burden of endemic HAI-SSI incidence was 11.8 per 100 surgical patients undergoing surgical procedures (95\% CI:8.6-16.0) and 5.6 per 100 surgical procedures $(95 \% \mathrm{CI}: 2.9-10.5){ }^{2} \mathrm{SSI}$ extends the postoperative hospitalization by an average of 9.7 days and increased health care and costs of US $\$ 20,842 .{ }^{3}$ In Mexico; in the years 2014 and 2015, the Department of Epidemiology of Health reported that there were 15 incidents of surgical site infection in 100 entries, the mortality was $25.5 \%$, the additional hospital stay ranged from 7 to 20.7 days, and the unit costs per episode was more than USD 6,005 per episode. ${ }^{3,4}$

Several prevention strategies and policies regarding the SSI prevention have been established, including preoperative bathing, surgical site preparation, antimicrobial skin, surgical hand preparation, antimicrobial prophylaxis ${ }^{5}$ and the most recent and updated one is the global guidelines for the prevention of surgical infection initiated by the WHO. While several evidence-based recommendations were established previously for the preoperative, trans-operative and postoperative prevention of surgical site infection, the WHO guideline is the first to recommend surgical wound irrigation as an important strategy.,3

\section{Specifications solutions, pressure, containers and axillary substances}

In México, orthopedic surgeons made a consensus in 2013 which recognized the theoretical basis of irrigation to reduce wound infection but without establishing specifications in methods and irrigation solution to be used. ${ }^{6}$ Saline irrigation reduces infection when compared with the non-irrigated cases. ${ }^{7,8}$ Irrigation pressure below 15 pounds per square inch (psi) and above 35 psi was regarded as low and high pressure respectively while the use of low pressure is recommended, as the use of high pressure causes damage to the adjacent tissue and the process of healing. ${ }^{9}$ Regarding the containers for the irrigation solution at the procedure field, one study showed that in 13 of 21 irrigating solutions in containers were contaminated at the end of the surgical procedures. ${ }^{10-12}$ Our experience recommends the use of sterile devices and adapters to avoid contamination of the solution and hence reduce SSI incidence.

The Food and Drugs Administration (FDA) has warned the inappropriate use of antibiotics in surgical wound irrigation as it increases antimicrobial resistance and reduces the effectiveness of established antibiotic treatments and increased health costs and mortality. ${ }^{13,14}$ The antiseptics are also commonly used (the most common one is the iodopovidone) in the surgical wound irrigation to exert a bactericidal effect, but it also lacks FDA's authorization. Evidence found it associated with cellular toxicity and delayed the healing process. Particularly, similar findings were observed in high concentrations sodium hydrogen, sodium hypochlorite and parachoroxylenol. ${ }^{15}$ The chlorhexidine gluconate $(\mathrm{CHG})$ at a concentration of $0.05 \%$ is one of the substances which is authorized and approved by the FDA for surgical wound irrigation due to its null toxicity for granulation and wound healing. It also has a beneficial effect on the prevention of SSI and should replace the inappropriate use of antiseptics or antibiotics. ${ }^{16}$ The $\mathrm{CHG}$ has a joint beneficial effect on the prevention of SSI with hand washing, skin preparation and sterile dressings covering the surgical wound. ${ }^{15,16}$ Besides, several studies suggested that the use of CHG for surgical wound irrigation was associated with improved patient recovery as well as reduced costs in health management. ${ }^{17-19}$ Currently, CHG $0.05 \%$ has been used in some hospital operating rooms in México. 


\section{Conclusion}

The national associations especially the operational health personnel should conduct research to strengthen their knowledge of the risk and protective factors and adherence to the protocols on the use of wound irrigation to prevent SSI. This practice has been well documented in Mexico, in terms of standardization of irrigation, sterilization policies, antiseptics and disinfectants, and reuse of disposable material. ${ }^{3,20}$ Currently, the Mexican national legislation for the epidemiological surveillance, prevention, and control of infections, emphasized the need to strengthen the existing system and to extend the coverage through effective information management which will maximize the effort to control infections, and specifically, surgical site infection. ${ }^{21}$

The role of nursing has been described and emphasized in each of the manuals, guides, protocols and studies as approximately up to $80 \%$ of the total of actions, procedures and techniques are done directly or indirectly by nurses in a health institution. ${ }^{22}$ The journey to control infection is long but progressing, we can increase the attachment and adherence of the evidence-based recommendations from research in order to improve the quality and safety of patients, and the prevention of infections associated with health care.

\section{Acknowledgements}

None.

\section{Conflict of interest}

The author declares no conflict of interest.

\section{References}

1. Magill S, Hellinger W, Cohen J, et al. Prevalence of healthcare-associated infections in acute care hospitals in Jacksonville, Florida. Infec Control Hosp Epidemiol. 2012;33(3):283-291.

2. World Health Organization. Global guidelines for the prevention of surgical site infection; 2016.

3. Ministry of Health México. Measurement of the prevalence of nosocomial infections in general hospitals of the main public health institutions; 2011

4. Hernandez OG, Castaneda NJ. Prevention of infections. A look at the new "Global guide to surgical site infection prevention. Acta Pediatr Mex. 2017;38(1):1-9.

5. Davide PV, Bruno A, Di Trapani B, et al. 2016 WHO global guidelines for the prevention of surgical site infection: a new step to improve patient's safety before, during and after surgery. Life safety and security. 2017;5(1):1-13.
6. Alijanipour P, Karam J. Surgical environment. Act Ort Mex. 2013;27(S1):S60-S81.

7. Cervantes SC, Gutierrez VR, Vazquez CJ, et al. Syringe pressure irrigation of subdermic tissue after appendectomy to decree the incidence of operative wound infection. Word J Surg. 2000;24:38-41.

8. Eklund AE, Tunevall TG. Prevention of postoperative wound infection after apprendicectomy by local application of tinidazole: a double-blind study. World J Surg. 1987;11(2):263-266.

9. Hassinger SM, Harding G, Wongworawat MD. High-pressure pulsatile lavage propagates bacteria into soft tissue. Clinic Orthop Relat Res. 2005;439:27-31.

10. Andersson BM, Lidgren L, Schalen C, et al. Contamination of irrigation solutions in an operating theatre. Infect Control. 1984;5(7):339-341.

11. Anto B, McCabe J, Kelly S, et al. Splash basin bacterial contamination during elective arthroplasty. J Infect. 2006;52(3):231-232.

12. Glait SA, Schwarzkopf R, Gould S, et al. Is repetitive intraoperative splash basin use a source of bacterial contamination in total joint replacement. J Orthopedics. 2011;34(9):e546-549.

13. Duarte RF, Rodríguez LM, De Anda GM, et al. Appropriate antimicrobial use in pediatrics in a third level hospital. Rev Med Inst Mex Seg Soc. 2015;53(2):150-157.

14. Savage JW, Anderson PA. An update on modifiable factors to reduce the risk of surgical site infection. Spine J. 2013;13(9):1017-1029.

15. Barnes S, Spencer M, Gram D, et al. Surgical wound irrigation: A call for evidence-based standardization of practice. Am J Infect Control. 2014;42(5):525-529.

16. Edmiston $\mathrm{CE}$, Bruden $\mathrm{B}$, Rucinski $\mathrm{MC}$, et al. Reducing the risk of surgical site infections: Does chlorhexidine gluconate provide a risk reduction benefit. Am J Infect Control. 2013;41(5 supply):S49-55.

17. Alison KJ, Higuera CA. Use of chlorhexidine preparations in total joint arthroplasty. J Bone Infect. 2017;2(1):15-22.

18. Smith DC, Maiman R, Schwechter EM, et al. Optimal irrigation and debridement of infected total joint implants with chlorhexidine gluconate. J Arthroplasty. 2015;30(10):1820-1822.

19. Shams WE, Hanley GA, Orvik A, et al. Peritoneal lavage using chlorhexidine gluconate at the end of colon surgery reduces postoperative intra-abdominal infection in mice. J Surg Res. 2015;195(1):121-127.

20. Escamilla Z. Incorporation of undergraduate research in nursing in México. Rev Cui. 2014;5(2):837-841.

21. Ministry of Health Mexican. Mexican Oficial Standard NOM-045 SSA2-2005. For the epidemiological surveillance, prevention and control of nosocomial infections; 2005

22. Castro RA. Role of nursing staff in prevention of nosocomial infections. Bogota: University CES of Medellin; 2014. 